\title{
A new approach for retrieving the UV-vis optical properties of ambient aerosols
}

\author{
Nir Bluvshtein, J. Michel Flores, Lior Segev, and Yinon Rudich \\ Department of Earth and Planetary Sciences, Weizmann Institute of Science, Rehovot 76100, Israel \\ Correspondence to: Yinon Rudich (yinon.rudich@weizmann.ac.il)
}

Received: 3 March 2016 - Published in Atmos. Meas. Tech. Discuss.: 30 March 2016

Revised: 28 June 2016 - Accepted: 29 June 2016 - Published: 1 August 2016

\begin{abstract}
Atmospheric aerosols play an important part in the Earth's energy budget by scattering and absorbing incoming solar and outgoing terrestrial radiation. To quantify the effective radiative forcing due to aerosol-radiation interactions, researchers must obtain a detailed understanding of the spectrally dependent intensive and extensive optical properties of different aerosol types. Our new approach retrieves the optical coefficients and the single-scattering albedo of the total aerosol population over 300 to $650 \mathrm{~nm}$ wavelength, using extinction measurements from a broadband cavity-enhanced spectrometer at 315 to $345 \mathrm{~nm}$ and 390 to $420 \mathrm{~nm}$, extinction and absorption measurements at $404 \mathrm{~nm}$ from a photoacoustic cell coupled to a cavity ring-down spectrometer, and scattering measurements from a three-wavelength integrating nephelometer. By combining these measurements with aerosol size distribution data, we retrieved the time- and wavelength-dependent effective complex refractive index of the aerosols. Retrieval simulations and laboratory measurements of brown carbon proxies showed low absolute errors and good agreement with expected and reported values. Finally, we implemented this new broadband method to achieve continuous spectral- and time-dependent monitoring of ambient aerosol population, including, for the first time, extinction measurements using cavity-enhanced spectrometry in the 315 to $345 \mathrm{~nm} \mathrm{UV} \mathrm{range,} \mathrm{in} \mathrm{which} \mathrm{significant} \mathrm{light}$ absorption may occur.
\end{abstract}

\section{Introduction}

Atmospheric aerosols affect Earth's energy balance directly via their interactions with incoming solar radiation and indirectly by altering cloud microphysical and optical proper- ties. The effective radiative forcing (ERF) due to aerosolradiation interactions (ERFari) encompasses attenuation of solar flux to the surface due to direct scattering and absorption and rapid adjustments of the atmospheric temperature profile (IPCC, 2013). The latter is caused by energy released as heat by light-absorbing aerosols that can influence cloud lifetime (Hill and Dobbie, 2008; Davidi et al., 2009; Allen and Sherwood, 2010; Koch and Del Genio, 2010; Nabat et al., 2014). Irradiation changes from ERFari and the ERF due to aerosol-cloud interactions (ERFaci) are still two of the largest uncertainties in the understanding of anthropogenic radiative forcing (IPCC, 2013).

Radiative transfer models use aerosol optical depth, single-scattering albedo (SSA), the scattering phase function, and the asymmetry parameter to describe the interaction between aerosols and solar radiation. An accurate representation of the complex refractive index (RI; $m=n+i k)$, which is an intensive optical property of aerosol types and components, is required to calculate these parameters.

Aerosol optical properties are typically measured as scattering, absorption, or extinction coefficients $\left(\alpha_{\mathrm{sca}}, \alpha_{\mathrm{abs}}\right.$, and $\alpha_{\text {ext }}$, respectively) by a variety of in situ techniques. These include integrating and reciprocal nephelometry (Nakayama et al., 2010), filter-based absorption measurements (Guyon et al., 2003; Zhang et al., 2013), photoacoustic spectrometry (PAS) (Lack et al., 2012), extinction cells, and cavityenhanced spectrometry (CES) (Varma et al., 2013). Many of these methods are restricted to a single or a few discrete wavelengths and their ability to provide wavelengthdependent measurements is limited. Broadband CES instruments were recently developed for aerosol extinction measurements at wavelength ranges of about 30 to $40 \mathrm{~nm}$ per cavity (Washenfelder et al., 2013, 2015; Zhao et al., 2013; 
Flores et al., 2014). White-type extinction cells with a UVvis light source and a grating spectrometer were recently used for aerosol extinction measurements over a wide range of wavelengths from below $250 \mathrm{~nm}$ up to $700 \mathrm{~nm}$. However, White-type extinction cells suffer from short optical path length (tens of meters, as opposed to several kilometers in CES instruments), which leads to the detection limit being an order of magnitude higher than that of CES (Chartier and Greenslade, 2012; Jordan et al., 2015).

Organic particulate matter that has strong wavelengthdependent light absorption characteristics, with higher absorption at near-ultraviolet and blue wavelengths (Andreae and Gelencser, 2006; Laskin et al., 2015), is known as atmospheric brown carbon $(\mathrm{BrC}) . \mathrm{BrC}$ is mostly composed of anthropogenic or biogenic secondary organic aerosols and aerosols from biomass burning (Spracklen et al., 2011). The contribution of $\mathrm{BrC}$ to radiative forcing still poses one of the largest uncertainties in our understanding of climate forcing. $\mathrm{BrC}$ may be the dominant light absorber downwind of urban and industrialized areas and in biomass burning plumes (Feng et al., 2013). In the atmosphere, it is found either internally or externally mixed with inorganic particles and black carbon (Cappa et al., 2012). If internally mixed with black carbon, $\mathrm{BrC}$ may cause absorption enhancement through the lensing effect (Bond et al., 2006). A better quantification of the spectral dependency of optical properties of $\mathrm{BrC}$ aerosols is required in order to reduce the uncertainty surrounding the ERFari.

The interaction of atmospheric fine particulate matter with sunlight was shown to resemble a power law dependence on wavelength decades ago (Ångström, 1929, 1930, 1961, 1964). The Angström exponent was since widely used to describe this wavelength dependency and to characterize aerosols size (Valenzuela et al., 2015), composition (Russell et al., 2010), and source (Garg et al., 2016). This monotonic increase in extinction (scattering and absorption) with increasing particle size or with decreasing wavelength is observed for particles with radii smaller than the incident wavelength (or size parameter $<2 \pi$ ). For larger particles (or shorter wavelengths) the ripple and interference structures of the Mie curves significantly reduce the monotonic increase pattern (Bohren and Huffman, 2007a). This also depends on the complex RI. Increasing the real part limits the power law behavior to smaller particles while increasing imaginary part, dampening the ripple and interference structures, allowing power law behavior for larger particles. Particulate matter with molecular absorption bands in the actinic flux spectrum would also deviate from the power law spectral dependency. In an ambient dust-free atmosphere as well as in many laboratory and chamber experiments, particles are rarely larger than several hundreds of nanometers, making the power law wavelength dependency assumption a reasonable one (Kirchstetter et al., 2004; Hoffer et al., 2006; Sun et al., 2007; Chen and Bond, 2010; Washenfelder et al., 2015).
In this study, we present a new approach for retrieving a broadband UV-vis spectrum (300 to $650 \mathrm{~nm}$ ) of the total aerosol population, including its $\alpha_{\mathrm{sca}}, \alpha_{\mathrm{abs}}$, and $\alpha_{\mathrm{ext}}$, its SSA, and, together with size distribution measurements, its effective wavelength-dependent complex RI. The new retrieval approach utilizes a combination of several different instruments: CES, PAS, and nephelometer. We validate the method with computer simulations and laboratory measurements and show how it can be applied for continuous spectral- and timedependent monitoring of an ambient polydisperse aerosols population. To the best of our knowledge, we also report the first implementation of broadband CES for aerosol extinction measurements in the 315 to $345 \mathrm{~nm} \mathrm{UV} \mathrm{range} \mathrm{(being} \mathrm{a} \mathrm{range}$ in which significant light absorption may occur) for laboratory and ambient aerosols.

\section{Methods}

\subsection{Approach}

To obtain the optical properties of light-absorbing ambient aerosols in the 300 to $650 \mathrm{~nm}$ wavelength range, we used measurements of $\alpha_{\text {ext }}, \alpha_{\text {sca }}$, and $\alpha_{\text {abs }}$. The extinction coefficients were obtained with a broadband cavity-enhanced spectrometer (BBCES) measuring at two distinct wavelength ranges: 315 to $345 \mathrm{~nm}$ and 390 to $420 \mathrm{~nm}$. Extinction and absorption coefficients at $\lambda=404 \mathrm{~nm}$ were measured using a homebuilt multi-pass PAS (Lack et al., 2012) coupled to a cavity ring-down spectrometer (CRD-S) (Bluvshtein et al., 2012; Flores et al., 2012) (PA-CRD-S). The scattering coefficients at 457, 525, and $637 \mathrm{~nm}$ were measured using an integrating nephelometer (IN; model IN100, AirPhoton, USA). The $\alpha_{\text {ext }}, \alpha_{\text {sca }}$, and $\alpha_{\text {abs }}$ measurements were used together with the aerosol size distribution and the aerosol number concentration in a novel procedure to obtain the broadband optical coefficients, the SSA, and the broadband effective complex RI in the 300 to $650 \mathrm{~nm}$ wavelength range. The procedure is described in detail in Sect. 2.3. The term effective complex RI is used to represent that we derive the RI for the entire aerosol size distribution. It is the complex RI from which, for the corresponding size distribution, we derive the optical coefficients that agree most closely with the measured or input values.

\subsection{Instrumentation}

\subsubsection{Broadband cavity-enhanced spectroscopy}

We use a dual-channel BBCES to measure the aerosol optical extinction between 315 to $345 \mathrm{~nm}$ and 390 to $420 \mathrm{~nm}$ (at a $0.5 \mathrm{~nm}$ resolution). The 315 to $345 \mathrm{~nm}$ cavity uses a new, laser driven Xe lamp, and its design is similar to that described by Washenfelder et al. (2016). The 390 to $420 \mathrm{~nm}$ cavity is as described in Flores et al. (2014). Only a brief description and the main differences are highlighted here. 
For the 390 to 420 nm cavity (BBCES-407), we use a lightemitting diode (LED) centered at $407.1 \mathrm{~nm}$ with a measured optical power output of $0.450 \mathrm{~W}$ (M405D2, Thorlabs, Newton, NJ, USA). The LED is temperature-controlled and powered by a constant-current power supply to achieve a stable optical power output. The output from the LED is collimated using a single F/1.2 fused silica lens and optically filtered using a bandpass filter (FB400-40, Thorlabs, Newton, NJ, USA) before entering the optical cavity formed by two mirrors, $2.54 \mathrm{~cm}$ in diameter and $1 \mathrm{~m}$ radius of curvature (Advanced Thin Films, Boulder, CO, USA). For the 315 to $345 \mathrm{~nm}$ cavity (BBCES-330; see Washenfelder et al. (2016) for a detail description), we use a broadband light source (EQ-99FC LDLS; Energetiq, Woburn, MA, USA) consisting of a continuous wave diode laser at $974 \mathrm{~nm}$ that pumps a Xe plasma (Islam et al., 2013). The light source is air-cooled and temperature-controlled using water circulation through an attached aluminum plate to prevent intensity drifts. This light exits through a $600 \mu \mathrm{m}$ optical fiber and it is collimated and coupled into the optical cavity using an off-axis parabolic mirror with a 0.36 numerical aperture (RC04SMAF01; Thorlabs, Newton, NJ, USA). To remove stray light, the light passes through two colored glass filters (Schott Glass WG320 and UG11) before entering the cavity. This cavity also consists of two mirrors, $2.54 \mathrm{~cm}$ in diameter and $1 \mathrm{~m}$ radius of curvature (Layertec $\mathrm{GmbH}$, Mellingen, Germany).

The typical measured mirror reflectivities for the BBCES330 and BBCES-407 cavities are 0.99940 and 0.99994 at 330 and $420 \mathrm{~nm}$, respectively. After exiting each cavity, the light is directly collected using a $0.1 \mathrm{~cm} \mathrm{F/2} \mathrm{fiber} \mathrm{collima-}$ tor (74-UV, Ocean Optics, Dunedin, FL, USA) into one lead of a two-way $100 \mu \mathrm{m}$ core HOH-UV-VIS fiber (SROPT-8015, Andor Technology, Belfast, UK) that is linearly aligned along the input slit of the grating spectrometer.

The spectra are acquired using a $163 \mathrm{~mm}$ focal length Czerny-Turner spectrometer (Shamrock SR-163, Andor Technology, Belfast, UK) with a charge coupled device (CCD) detector (DU920P-BU, Andor Technology, Belfast, $\mathrm{UK})$ maintained at $-50^{\circ} \mathrm{C}$. The spectrometer is temperaturecontrolled at $32.0 \pm 0.1^{\circ} \mathrm{C}$. Dark spectra are acquired with the input shutter (SR1-SHT-9003, Andor Technology, Belfast, UK) closed prior to each set of spectra. The wavelength is calibrated using a $\mathrm{Hg} / \mathrm{Ar}$ pen-ray lamp.

The $\alpha_{\text {ext }}$ of the aerosol is determined as the difference in light intensity between a filled cavity and a particle-free cavity, taking into account the mirror reflectivity and the Rayleigh scattering of the carrier gas (Washenfelder et al., 2013).

\subsubsection{Photoacoustic spectrometer coupled to a cavity ring-down spectrometer}

A single-wavelength PA-CRD-S (Fig. 1) is used to directly measure both $\alpha_{\text {ext }}$ and $\alpha_{\text {abs }}$ at $\lambda=404 \mathrm{~nm}$. The PA-CRD-S system described in this section (Fig. 1) is composed of a
$110 \mathrm{~mW} 404 \mathrm{~nm}$ diode laser (iPulse, Toptica Photonics, Munich, Germany) modulated at the measured PAS resonance frequency at $50 \%$ duty cycle. The laser beam (blue arrow in Fig. 1) is split into two separate optical paths (directed to the CRD-S and the PAS, respectively) using a variable beam splitter composed of a quarter waveplate $(1 / 4 \lambda)$ and a polarizing beam splitter (PBS). With the current setup, turning the $1 / 4 \lambda$ between $0^{0}$ and $90^{\circ}$ varies the intensity ratio between the two optical paths from $0: 1$ to $1: 1 \mathrm{CRD}-\mathrm{S}$ to PAS, respectively. The beam directed to the PAS is turned and aligned into the PAS cell through a set of two planoconvex lenses (focal lengths of 30 and $50 \mathrm{~mm}$ ) used as a telescope in order to collimate the beam into a diameter of about $1.5 \mathrm{~mm}$. The beam directed to the CRD-S passes through another $1 / 4 \lambda$ plate, which together with the PBS serves as a variable attenuator protecting the laser head from the beam reflected back by the highly reflective mirror of the CRD$\mathrm{S}$. This back-reflected beam is transmitted through the PBS into a photodiode (PD) (as shown by the dashed arrow in Fig. 1), with the PD serving as an external trigger source for the CRD-S decay measurement. The forward beam is then turned and aligned into the CRD-S cavity by a set of turning mirrors. While the sensitivity of the PAS is related to the power intensity of the laser, the CRD-S system requires only the minimal laser power needed by the PD. This allows us to divert approximately $78 \%$ of the laser power (about $86 \mathrm{~mW}$ ) to the PAS cell and thus optimize its sensitivity.

\subsection{3 a. Photoacoustic spectrometer}

In a PAS, modulated laser light is absorbed by a sample of particles or gas, generating a modulated acoustic wave whose intensity is proportional to the energy absorbed by the sample. This acoustic wave, which is detected by a sensitive microphone, has a characteristic radial and longitudinal resonance when the light source is modulated at the cavity resonance frequency. For a more detailed description of the PAS method for aerosol light absorption measurement see Arnott et al. (1999) and Nagele and Sigrist (2000).

We use a multi-pass astigmatic PAS cell (see Lack et al., 2012, for a detailed description). Briefly, the PAS is composed of dual half-wavelength resonators $(11 \mathrm{~cm}$ long, $1.9 \mathrm{~cm}$ diameter) capped on either end with quarter-wavelength acoustic notches. The total sample cell volume is $185 \mathrm{~cm}^{3}$. While both resonators are open to sample flow, only one is exposed to the modulated laser light; the other is used for noise cancellation. Microphones are placed at the antinode of the sound wave in the center of each resonator and the speaker is placed at the background resonator. The resonance frequency specific to this system is found by producing white noise using a speaker in the reference resonator. Each segment is sampled by the microphones at a $100 \mathrm{kHz}$ rate and analyzed by a fast Fourier transform algorithm.

The astigmatic optical configuration consists of two $5.08 \mathrm{~cm}$ diameter, high-reflectivity mirrors (ARW Opti- 


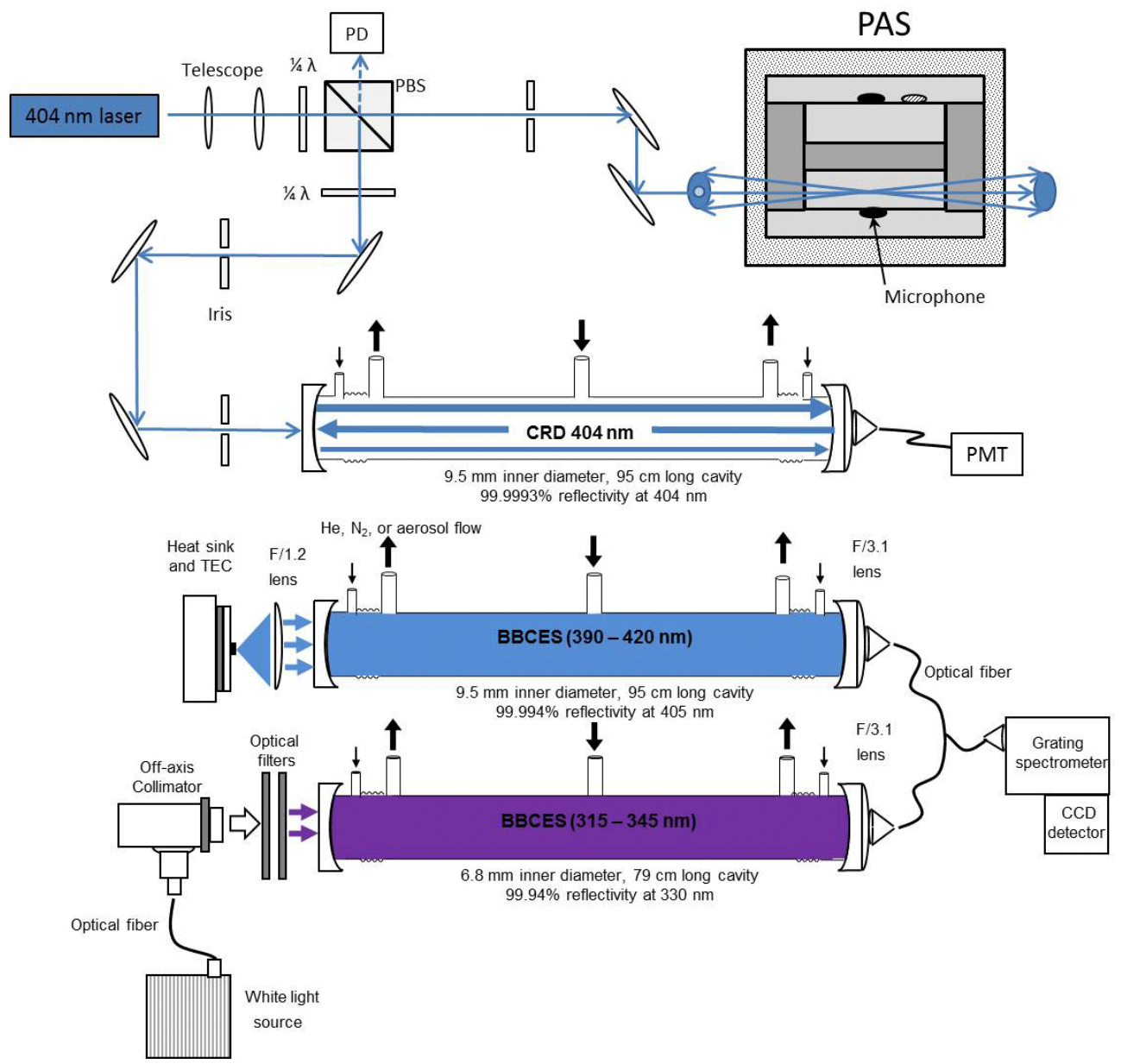

Figure 1. Schematic of the photo-acoustic spectrometer (PAS) coupled to a cavity ring-down (CRD) spectrometer (PA-CRD-S) and of the broadband cavity-enhanced spectrometer (BBCES), with channels for 315 to 345 and 390 to $420 \mathrm{~nm}$. The optical cavity of the CRD-S and the two optical cavities of the BBCES were assembled together in a rigid optical cage to minimize alignment stability issues. CCD is charge coupled device; PBS is polarizing beam splitter; PD is photodiode; PMT is photomultiplier tube; TEC is thermoelectric cooler. The small black arrows indicate the entrance of the purge flows, and the thicker black arrows indicate the direction of the aerosol flow.

cal, Wilmington, NC, USA; dielectric coating $R>99.5 \%$ ) spaced $35 \mathrm{~cm}$ apart and mounted on adjustable mirror mounts. The laser side mirror has a cylindrical radius of curvature of $43 \mathrm{~cm}$ and a $2 \mathrm{~mm}$ hole drilled in the center. The back mirror has a cylindrical radius of curvature of $47 \mathrm{~cm}$ and is rotated $90^{\circ}$ to the radius of curvature of the laser side mirror. Astigmatic alignment is achieved by aligning the laser through the $2 \mathrm{~mm}$ hole drilled in the center of the first mirror and onto an off-center target on the second mirror. Each following reflection should also be directed to an off-center target on the other mirror. The PAS cell is mounted within the path of the laser multi-pass. The laser light passes through the PAS cell via two $1 \mathrm{~mm}$ thick windows (CVI Laser, Albuquerque, NM, USA), each with a high-transmissivity $(T>99.5 \%)$ anti-reflective coating. The laser power is continuously monitored using a photodiode behind the back side mirror and used to cancel variations in acoustic signal related to laser power fluctuations.
The PAS calibration procedure is described in detail in a companion paper. In short, the complex RI of dry nigrosine films is measured at $404 \mathrm{~nm}$ using spectroscopic ellipsometry with the interference enhancement technique (Hilfiker et al., 2008). Nigrosine dye is dissolved into an aqueous solution and nebulized using a constant output atomizer (model 3076 , TSI, 35 psi, flow of 2.5 standard $\mathrm{L} \mathrm{min}^{-1}$ ), with dry particle-free nitrogen, generating a polydispersed distribution of droplets. The aerosol population is subsequently dried (relative humidity $(\mathrm{RH})<5 \%$ ) using two silica gel diffusion dryers and size-selected with an electrostatic classifier (differential mobility analyzer (DMA) model 3085, TSI), operating with a particle-free, dry nitrogen sheath flow of 3 to 15 standard L $\mathrm{min}^{-1}$. A $10: 1$ ratio of sheath flow to sample flow is maintained. An impactor is used on the DMA inlet to reduce the contribution from multiply charged particles. Nigrosine particles of several sizes (200 to $400 \mathrm{~nm}$ mobility diameter) and number concentrations (counted by a 
condensation particle counter; CPC; model 3775, TSI) were flowed through the PAS cell and its signal was compared to the aerosol $\alpha_{\text {abs }}$ calculated using the complex RI retrieved from the dry film measurements and a Mie algorithm.

\section{b. Cavity ring-down spectrometer}

The CRD-S method has been extensively described in previous publications (Sappey et al., 1998; Vander Wal and Ticich, 1999; Smith and Atkinson, 2001; Bulatov et al., 2002; Thompson et al., 2002; Strawa et al., 2003; Pettersson et al., 2004; Riziq et al., 2007; Bluvshtein et al., 2012). Briefly, a single-wavelength laser light source is modulated and coupled into the high-finesse optical cavity. The cavity transmission is coupled to an optical fiber and focused onto a photomultiplier tube (PMT), which measures the decay of the light intensity due to aerosol absorption and scattering (extinction). Measuring the light time constant, with an empty cavity and with a cavity filled with aerosols, allows the direct measurement of $\alpha_{\text {ext }}$.

The two optical cavities of the BBCES and the optical cavity of the CRD-S were assembled together in a rigid optical cage to minimize alignment and instabilities. Aerosol flow was introduced to the center of each cavity and pulled from its sides (Fig. 1, downward arrows into the CRD-S and BBCES). This setup eliminates a significant source of error in determining the extinction coefficient, namely, uncertainty in the length of the aerosol sample within the cavity length (Miles et al., 2011). The optical cage and the PAS cell are mounted on vibration-isolated breadboard in a temperature controlled environment $\left(23 \pm 0.25^{\circ} \mathrm{C}\right)$.

\subsubsection{Integrating nephelometer}

The AirPhoton IN100 IN is a component of the global Surface PARTiculate Aerosol Network (SPARTAN), whose purpose is to evaluate and enhance satellite-based estimates of ground level particulate matter. The nephelometer is a continuous sampling, LED-based device measuring total $\alpha_{\mathrm{sca}}$ at three optical channels (red, green, and blue) centered on 637, 525 , and $457 \mathrm{~nm}$ over an angular range of 7 to $170^{\circ}$ (Snider et al., 2015).

\subsubsection{Size distribution and number concentration}

Aerosol number concentration is measured with a condensation particle counter (CPC; model 3775, TSI) and the particle size distributions are obtained by a scanning mobility particle sizer (SMPS; 3085 DMA and 3775 CPC, TSI).

\subsection{Retrieval methodology}

We have developed a two-step method to derive continuous values of $\alpha_{\text {ext }}, \alpha_{\text {sca }}, \alpha_{\mathrm{abs}}$, and SSA in the 300 to $650 \mathrm{~nm}$ wavelength range. Using these values of $\alpha_{\text {ext }}, \alpha_{\text {sca }}$, and $\alpha_{\text {abs }}$ together with the measured aerosol size distribution and the number concentration, we also retrieve the effective complex RI. A flow chart of the retrieval methodology is shown in Fig. 2.

\subsubsection{Broadband extinction, scattering, absorption, and SSA retrieval methodology}

First, the extinction data from the BBCES measurements ( 315 to $345 \mathrm{~nm}, 390$ to $420 \mathrm{~nm}$ ) are fitted with a power law function. The fitting procedure is weighted by the uncertainties of the measured BBCES extinction coefficients. This fit is used to extrapolate $\alpha_{\text {ext }}$ and its uncertainty to the nephelometer wavelengths. Next, data for $\alpha_{\mathrm{abs}}$ at $404 \mathrm{~nm}$ are used together with an initial guess of a power law coefficient to calculate $\alpha_{\mathrm{abs}}$ at the three nephelometer wavelengths (637, 525 , and $457 \mathrm{~nm}$ ) also considering the uncertainty of the measured $\alpha_{\mathrm{abs}}$ at $404 \mathrm{~nm}$. These three $\alpha_{\mathrm{abs}}$ values, together with the three $\alpha_{\text {ext }}$ values from the power law fit of the extinction data, are used to calculate $\alpha_{\text {sca_calc }}$ at the nephelometer wavelengths. Uncertainties of $\alpha_{\text {sca_calc }}$ are propagated from uncertainties of the extrapolated $\alpha_{\text {ext }}$ and $\alpha_{\text {abs. }}$. Then, the minimum square difference $\left(\chi^{2}\right)$ is calculated between $\alpha_{\text {sca_calc }}$ and the measured $\alpha_{\text {sca_meas }}$ using the uncertainties of both parameters, and the power law coefficient used to extrapolate the $\alpha_{\mathrm{abs}}$ data is varied iteratively until the minimum difference between $\alpha_{\text {sca_calc }}$ and $\alpha_{\text {sca_meas }}$ is found (Fig. 2a). This procedure is repeated with an exponential function to extrapolate $\alpha_{\text {ext }}$ and with an exponential coefficient to extrapolate $\alpha_{\text {abs }}$ and two additional times to cover all four possible combinations of exponential and power law representations of $\alpha_{\text {ext }}$ and $\alpha_{\text {abs }}$. At each repetition, the minimum difference between $\alpha_{\text {sca_calc }}$ and $\alpha_{\text {sca_meas }}$ is found iteratively and the global minimum difference from the four combinations is selected. This information is used to calculate $\alpha_{\mathrm{ext}}, \alpha_{\mathrm{abs}}$, and their associated uncertainties in the wavelength range of 300 to $650 \mathrm{~nm}$ (Fig. 2a) using the best-fitted power law or exponential curves, and $\alpha_{\text {sca }}$ is then calculated by subtraction. Finally, the size-weighted SSA is calculated as $\mathrm{SSA}=\alpha_{\text {sca }} / \alpha_{\text {ext }}$.

\subsubsection{Methodology for retrieving the effective complex RI of the total particle size distribution}

Using the retrieved $\alpha_{\mathrm{ext}}$ and $\alpha_{\mathrm{sca}}$ and their associated uncertainties described in Sect. 2.3.1 together with the measured size distribution and the aerosol number concentration, the effective complex RI of the total particle size distribution is retrieved at each individual wavelength ( 300 to $650 \mathrm{~nm}$ ). The effective complex RI in the context of this work is one that, for a given size distribution and number concentration, would satisfy a minimum difference between the theoretical values of $\alpha_{\text {ext }}$ and $\alpha_{\text {sca }}$ (based on a Mie theory calculation) and the extrapolated or measured $\alpha_{\text {ext }}$ and $\alpha_{\mathrm{sca}}$. A specialized Mie theory algorithm was written in order to retrieve the effective complex RI for the total size distribution of the parti- 

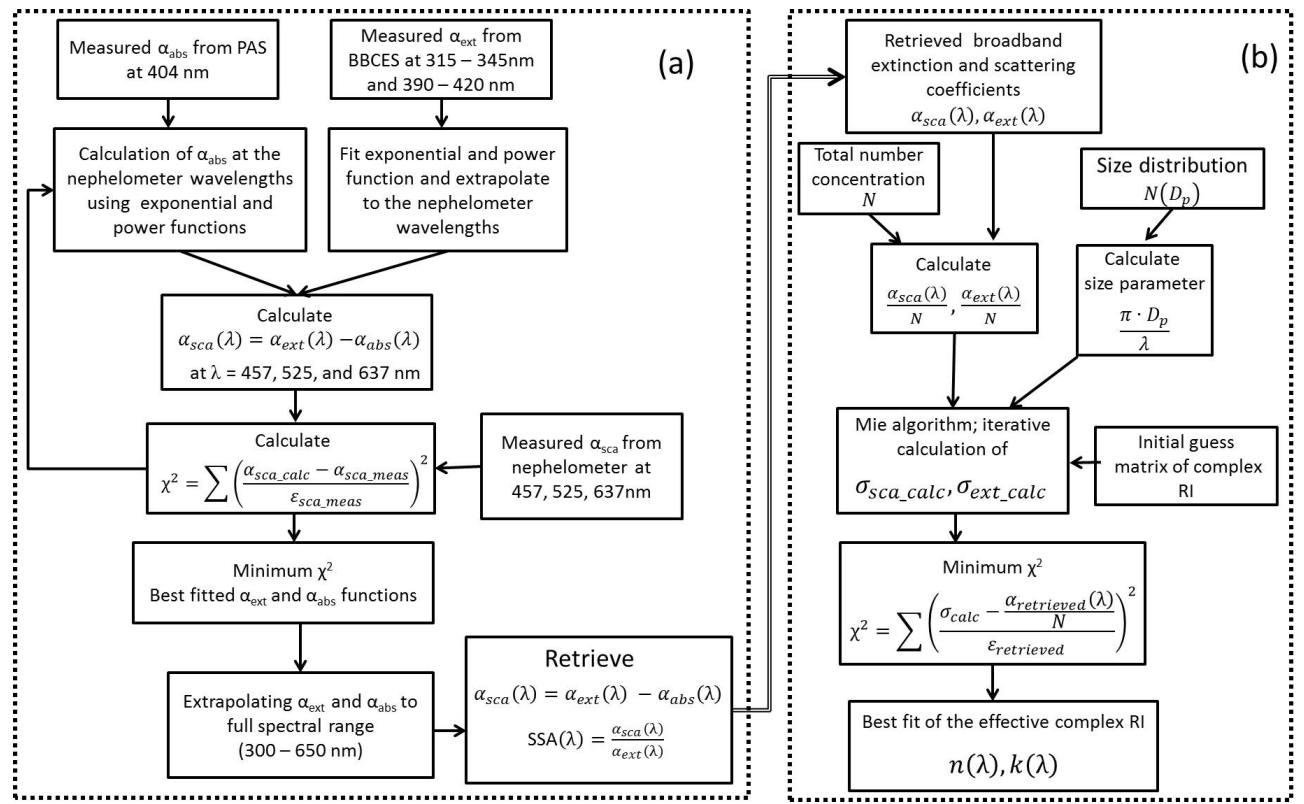

Figure 2. (a) Flow diagram for the new retrieval methodology. (b) Schematic of the method for retrieving the effective complex refractive index using the total particle size distribution. $\alpha_{\mathrm{abs}}, \alpha_{\text {ext }}$, and $\alpha_{\text {sca }}$ are wavelength-dependent absorption, extinction, and scattering coefficients, respectively; BBCES is broadband cavity-enhanced spectrometer; the subscripts calc and meas indicate a calculated or measured value, respectively; $D_{\mathrm{p}}$ is particle diameter; $n$ is the real part of the complex refractive index; $k$ is the imaginary part of the complex refractive index; $N$ is particle number concentration; PAS is photo-acoustic spectrometer; RI is effective complex refractive index; $\sigma_{\text {ext_calc }}$ and $\sigma_{\text {sca_calc }}$ are theoretical extinction and scattering cross sections weighted by the size distribution; $\chi^{2}$ is minimum square difference; $\omega$ is size-weighted single-scattering albedo (SSA).

cles. Briefly, an array of initial guesses is used to initiate an iterative converging search of a theoretical complex RI for which a Mie calculation (Bohren and Huffman, 2007b) with a given size distribution, number concentration, and wavelength produces a best-fitted pair of theoretical $\alpha_{\text {ext }}$ and $\alpha_{\text {sca }}$ (see Fig. 2b). The best fit is determined by minimizing the $\chi^{2}$ function:

$\chi^{2}=\frac{\left(\frac{\alpha_{\text {ext_meas }}}{N}-\sigma_{\text {ext_calc }}\right)^{2}}{\left(\frac{\mathrm{d} \alpha_{\text {ext }}}{N}\right)^{2}+\left(\frac{-\alpha_{\text {ext }} \times d N}{N^{2}}\right)^{2}}+\frac{\left(\frac{\alpha_{\text {sca_meas }}}{N}-\sigma_{\text {sca_calc }}\right)^{2}}{\left(\frac{\mathrm{d} \alpha_{\text {sca }}}{N}\right)^{2}+\left(\frac{-\alpha_{\text {sca }} \times \mathrm{d} N}{N^{2}}\right)^{2}}$,

where $\alpha_{\text {ext_meas }}$ and $\alpha_{\text {sca_meas }}$ are the retrieved or measured $\alpha_{\text {ext }}$ and $\alpha_{\text {sca }}, N$ is the particle number concentration, $\sigma_{\text {ext_calc }}$ and $\sigma_{\text {sca_calc }}$ are the theoretical extinction and scattering cross sections weighted by the size distribution, and $d$ denotes the uncertainty on the associated parameter.

To estimate the retrieval uncertainties in $n$ and $k$ ( $\Delta n$ and $\Delta k)$, the algorithm returns the values of $n$ and $k$ that satisfy $\chi_{0}^{2} \leq \chi^{2} \leq \chi_{0}^{2}+1$, where the value 1 denotes $1 \sigma$ deviation from the minimum $\chi^{2}\left(\chi_{0}^{2}\right)$ (in the case of 1 degree of freedom) (Press et al., 1992).

\subsection{Validation of the retrieval methodology}

In order to test this new approach and evaluate its merits, we performed three different tests: (1) a computer simulation of time-dependent extinction, scattering, and absorption measurements at the instruments' wavelengths; (2) laboratory measurements of two BrC proxy materials; and (3) a $24 \mathrm{~h}$ ambient aerosol measurement.

\subsubsection{Computer simulation}

For the computer simulation, 100 different synthetic data sets of complex RIs in the 300 to $650 \mathrm{~nm}$ range were composed at a resolution of $1 \mathrm{~nm}$. The real part $(n(\lambda))$ ranged from 1.692 at $300 \mathrm{~nm}$ to 1.586 at $650 \mathrm{~nm}$, and the imaginary part $(k(\lambda))$ ranged from $8.156 \times 10^{-2}$ at $300 \mathrm{~nm}$ to $1.781 \times 10^{-3}$ at $650 \mathrm{~nm}$. Both $n(\lambda)$ and $k(\lambda)$ were scaled by two incoherent sine waves to simulate temporal variability. The sine waves amplitude ranged from 1 to 1.05 for $n(\lambda)$ and from 1 to 1.1 for $k(\lambda)$. A log-normal size distribution with a mode at $80 \mathrm{~nm}$, a geometric standard deviation of 1.33, and a number concentration of $10^{4} \mathrm{~cm}^{-3}$ were assumed to calculate $\alpha_{\text {ext }}$, $\alpha_{\text {sca }}$, and $\alpha_{\text {abs }}$ at the instrumental wavelengths. An additional error was assigned to each calculated $\alpha_{\text {ext }}, \alpha_{\text {sca }}$, and $\alpha_{\text {abs }}$ at the instrumental wavelengths, randomly out of a normal distribution with $\pm 2 \%$ (1 standard deviation). This value of error represents typical uncertainty values associated with our 


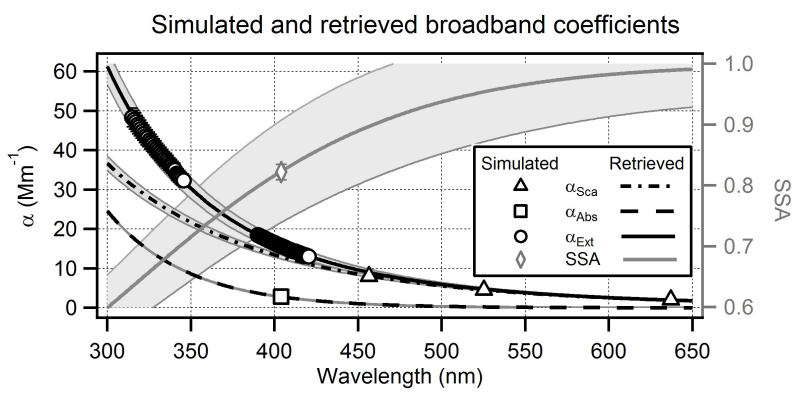

Broadband complex refractive index

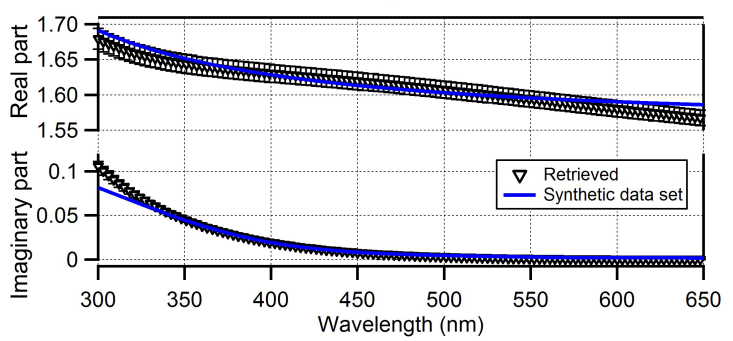

Figure 3. (a) Simulated wavelength-dependent extinction $\left(\alpha_{\text {ext }}\right.$; circles), scattering ( $\alpha_{\text {sca }}$; triangles), and absorption ( $\alpha_{\text {abs }}$; square) coefficients from the synthetic complex refractive index (RI) shown in the lower panel (blue lines). The retrieved broadband $\alpha_{\text {ext }}$ (black line), $\alpha_{\text {sca }}$ (dash-dot line), and $\alpha_{\mathrm{abs}}$ (dashed line) and singlescattering albedo (SSA; grey line and right axis) are also shown. (b) The synthetic complex RI (blue line) and the retrieved effective complex RI (inverted triangles), divided into their real and imaginary parts.

instrumental measurements. The $\alpha_{\text {ext }}, \alpha_{\text {sca }}, \alpha_{\text {abs }}$, SSA, and effective complex RI were then retrieved as described above for all the synthetic instrumental data sets. Figure 3 shows a single modeled example of the procedure. The retrieved $\alpha_{\text {ext }}$, $\alpha_{\text {sca }}, \alpha_{\text {abs }}$, and SSA are shown in Fig. 3a and the broadband complex RI in Fig. 3b.

\subsubsection{Laboratory measurements}

For the laboratory measurements, two BrC proxy materials were used to test the retrieval method: Suwannee River fulvic acid (SRFA; 1S101F, International Humic Substances Society (IHSS), Saint Paul, MN, USA) and Pahokee Peat fulvic acid (PPFA; IHSS). SRFA and PPFA (aquatic/terrestrialbased fulvic acids standards) have been used as proxy materials for atmospheric BrC (Dinar et al., 2008) since macromolecular organic substances in aerosols began to be analyzed (Hoffer et al., 2006; Gaffney et al., 2015) and are recognized as similar to humic and fulvic acids. Although Graber and Rudich (2006) highlighted significant chemical and physical differences between atmospheric humic-like substances and terrestrial or aquatic humic substances, for the purpose of simulating UV-vis light absorption by atmospheric BrC, terrestrial/aquatic-based humic substances standards remain useful.
Each substance was separately dissolved into an aqueous solution and nebulized as described in Sect. 2.2.2a. A complementary $\mathrm{N}_{2}$ flow of 1.3 standard $\mathrm{L} \mathrm{min}^{-1}$ was added and mixed with the sample flow, which was then introduced to the IN and subsequently split equally to the SMPS, CPC, PAS, and a three-cavity optical cage that contained the CRD-S and BBCES (see Fig. S2). There was no additional dilution of the sample flow once it was introduced to the IN to avoid differences in the sampled particle concentration between the different instruments. Aerosol temperature, pressure, and RH were measured continuously.

\subsubsection{Ambient aerosol measurement}

To demonstrate the application of the retrieval methods to field applications, ambient aerosols were sampled during a $24 \mathrm{~h}$ period. Using conductive tubing, ambient air was pulled from the roof of the Department of Earth and Planetary Sciences building at the Weizmann Institute of Science through a $\mathrm{PM}_{10}$ sampling inlet. Sampled air was dried $(\mathrm{RH}<17 \%)$ with diffusion dryers and pulled isokinetically through the PA-CRD-S and BBCES. A total flow of 16.7 standard $\mathrm{L} \mathrm{min}^{-1}$ was pulled through the $\mathrm{PM}_{10}$ inlet as specified by the manufacturer. The CRD-S and the two BBCES systems sampled at a 0.2 standard $\mathrm{L} \mathrm{min}^{-1}$ flow rate and the PAS at a 0.6 standard $\mathrm{L} \mathrm{min}^{-1}$ flow rate (Fig. S2). The flow scheme was set up in a manner that ensured isokinetic splitting at every tube junction. Sampling was undertaken continuously for a $24 \mathrm{~h}$ period from 18:30 LT (local time) on 21 June 2015 to 18:30 LT of the following day. While each instrument has a different sampling rate, in order to simplify data analysis, the data outputs of the PAS-CRD-S, BBCES, IN, and CPC were set to represent 2 min averages.

Because the IN continually samples untreated ambient aerosols as part of the SPARTAN network, it remained on the roof. For this reason, IN measurements had to be corrected for particle hygroscopic growth. Snider et al. (2015) suggest correcting for increased scattering due to the growth of humidified particles using the relative change in particle volume, but this does not take into account the decrease in effective RI of the particles due to water uptake. See the Supplement for a detail description of the correction we used.

\section{Results and discussion}

\subsection{Computer simulations}

The results of the computer simulations are summarized in Fig. 4. Box plots of the absolute value of the percent errors for the retrieved variables from the 100 different synthetic data sets are shown. Overall, the retrieved values are in very good agreement with the synthetic data. Results show that expected errors in the size-weighted SSA $(\lambda, t), \alpha_{\text {ext }}(\lambda, t)$, and $\alpha_{\text {sca }}(\lambda, t)$ are less than $10 \%$ for the full spectral range and less than $5 \%$ in the 400 to $500 \mathrm{~nm}$ range. Expected er- 


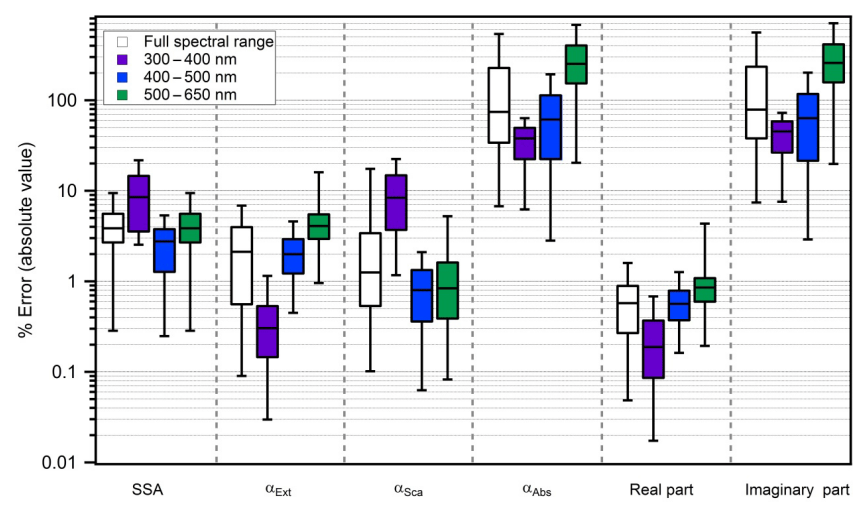

Figure 4. Box plot of the absolute value percentage errors for the retrieved variables from 100 different synthetic data sets of effective complex refractive indexes. The horizontal line within the box indicates the median, the boundaries of the box indicate the 25th and 75th percentile values, and the whiskers indicate the 5th and 95th percentile values of the results. Real and imaginary parts refer to the real and imaginary components of the refractive index. SSA is size-weighted single-scattering albedo; $\alpha_{\text {abs }}, \alpha_{\text {ext }}$, and $\alpha_{\text {sca }}$ are wavelength-dependent absorption, extinction, and scattering coefficients, respectively.

rors in the real part of the RI are less than $1 \%$ throughout the entire spectrum. Relative errors in the imaginary part of the $\mathrm{RI}$ and in $\alpha_{\mathrm{abs}}(\lambda, t)$ are less than $60 \%$ for the 300 to $400 \mathrm{~nm}$ range and are expected to grow with increasing wavelength as these parameters go to 0 . For example, under the conditions of this simulation at $400 \mathrm{~nm}$ wavelength (namely, the complex RI, particle size distribution, and number concentration), a relative error of $60 \%$ in the retrieved values translates into absolute errors of 1 to $3 \mathrm{Mm}^{-1}$ on $\alpha_{\mathrm{abs}}$ and of 0.01 to 0.015 on $k$, respectively. An absolute error of 1 to $3 \mathrm{Mm}^{-1}$ on $\alpha_{\text {abs }}$ at $400 \mathrm{~nm}$ is between 1 and $10 \%$ of measured absorption in polluted urban environments (Lack et al., 2012; Lan et al., 2013; Yuan et al., 2016).

\subsection{Laboratory measurements}

Figure 5 shows the measured optical coefficients of PPFA particles as well as the retrieved products of the broadband coefficients (Fig. 5a). The retrieved complex RI is also shown (Fig. 5b). The retrieved values for RI obtained by the established method of size-selecting aerosols (Lack et al., 2006; Riziq et al., 2007; Trainic et al., 2011; Bluvshtein et al., 2012; Flores et al., 2012, 2014; Lavi et al., 2013; Washenfelder et al., 2013) using the BBCES-315 and CRD-S are overlaid on Fig. 5b. The imaginary part of the complex RI calculated from UV-vis absorption measurements of the diluted aqueous solution (Sun et al., 2007) is shown as a shaded area. The upper and lower limits of this area represent the range of assumed material density $\left(1.1\right.$ to $\left.1.3 \mathrm{~g} \mathrm{~cm}^{-3}\right)$ used in this calculation. There is very good agreement between all the retrieved values, with a slight difference between them only
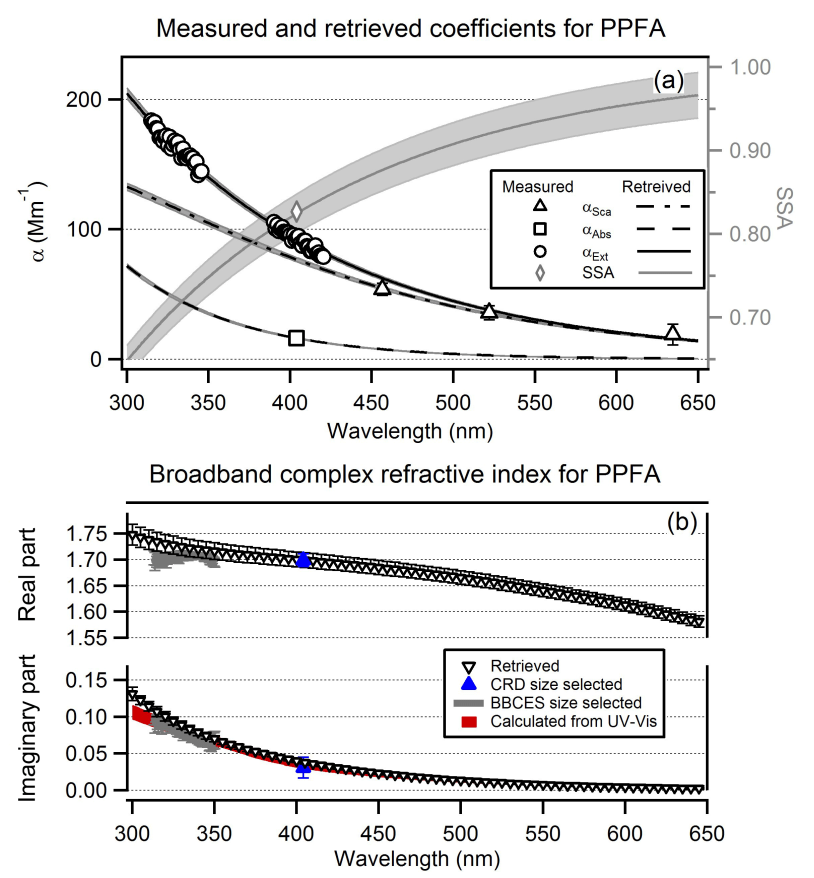

Figure 5. (a) Measured extinction (circles), scattering (triangles), and absorption (square) coefficients $\left(\alpha_{\text {ext }}, \alpha_{\text {sca }}\right.$, and $\alpha_{\text {abs }}$, respectively) for Pahokee peat fulvic acid (error bars representing measurement standard error are partially smaller than the symbols). The retrieved values for broadband extinction (black line), scattering (dash-dot line), absorption (dashed line), and single-scattering albedo (SSA; grey line) are also shown with shaded areas represent propagated uncertainty. (b) Retrieved broadband complex refractive index for Pahokee peat fulvic acid using (1) the retrieved RI from the data shown in (a) (inverted triangles) and (2) size selection measurements for the broadband cavity-enhanced spectrometer (BBCES-315; grey line) and the cavity ring-down spectrometer (CRD-S) at $404 \mathrm{~nm}$ (blue triangles). The imaginary part of the refractive index calculated from UV-vis absorption measurements is indicated by the red shaded area.

with respect to the real part of the RI in the 315 to $345 \mathrm{~nm}$ range.

Similarly to the PPFA measurements, Fig. 6 shows the measured and retrieved values for $\alpha_{\text {ext }}, \alpha_{\text {sca }}, \alpha_{\mathrm{abs}}$, and SSA obtained using SRFA as the $\mathrm{BrC}$ proxy material. Overlaid on Fig. $6 \mathrm{~b}$ are the published complex RI values retrieved from laboratory-generated SRFA. These retrievals were obtained from extinction measurements on size-selected particles. The accuracy of the new effective RI retrieval process is improved by incorporating direct absorption and scattering measurements as suggested by Zarzana et al. (2014).

\subsection{Ambient aerosol measurement}

We measured the optical properties of ambient aerosol during a $24 \mathrm{~h}$ period to demonstrate the application of the new retrieval methods. To check the reliability of the retrieval method, we first compared the SSA values at $404 \mathrm{~nm}$ de- 

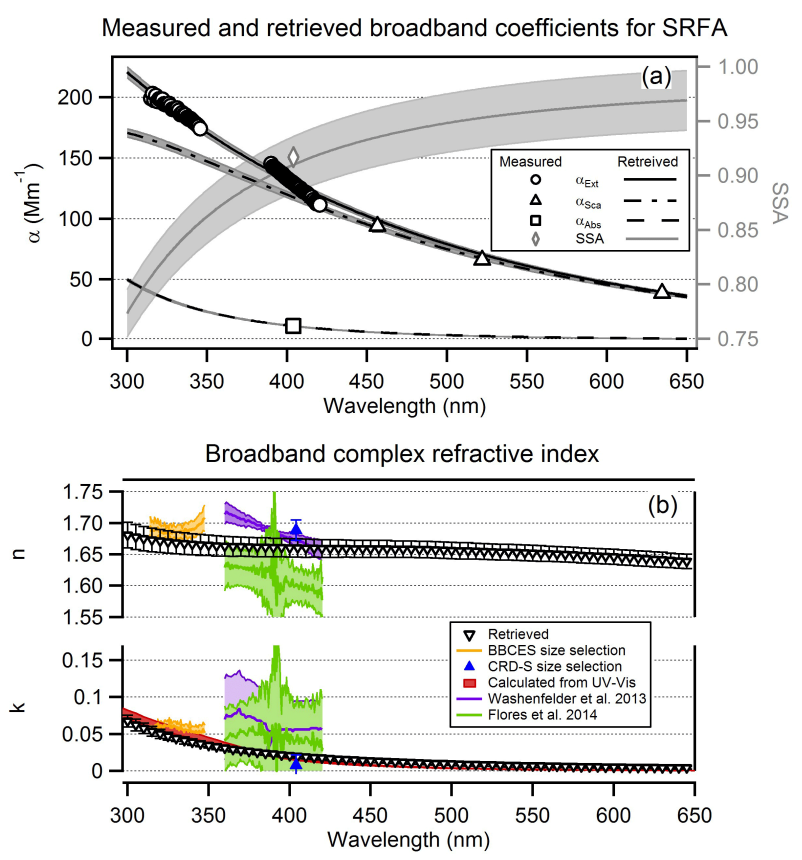

Figure 6. (a) Measured extinction (circles), scattering (triangles), and absorption (square) coefficients $\left(\alpha_{\text {ext }}, \alpha_{\text {sca }}\right.$, and $\alpha_{\text {abs }}$, respectively) for Suwannee River fulvic acid (error bars representing measurement standard error are smaller than the symbols). The retrieved broadband extinction (black line), scattering (dash-dot line), absorption (dashed line) and single-scattering albedo (SSA; grey line) are also shown with shaded areas represent propagated uncertainty. (b) Retrieved broadband complex refractive index (RI) for Suwannee River fulvic acid using (1) the retrieved RI from the data shown in (a) (inverted triangles) and (2) size selection measurements for the broadband cavity-enhanced spectrometer (BBCES-315; orange line) and the cavity ring-down spectrometer (CRD-S) at $404 \mathrm{~nm}$ (blue triangles); and (3) from the published data of Washenfelder et al. (2013) (purple line) and Flores et al. (2014) (green line). The imaginary part of the refractive index calculated from UV-vis absorption measurements is indicated by the red shaded area.

rived from the direct $\alpha_{\text {ext }}$ and $\alpha_{\text {abs }}$ measurements (using the PA-CRD-S), with the retrieved SSA (calculated from retrieved $\alpha_{\text {ext }}$ and $\alpha_{\text {sca }}$, Fig. 7) accounting for the uncertainties in both variables. Figure 7 shows an excellent correlation (slope $=1.031 \pm 0.291 ; R^{2}=0.977$ ) between the measured and retrieved SSA throughout the measurement period. Figures S3 (and S4) in the Supplement shows the good agreement between the retrieved and measured scattering (and extinction) coefficients at the nephelometer wavelengths (and at the center wavelengths of the two BBCES cavities). The good agreement between the measured and retrieved SSA is an indication that the broadband extinction retrieval procedure has little to no error at the wavelength at which the aerosol absorption is constrained. The full spectral retrievals of $\alpha_{\text {ext }}(\lambda, t), \alpha_{\text {sca }}(\lambda, t), \alpha_{\text {abs }}(\lambda, t)$ and $\operatorname{SSA}(\lambda, t)$ over time are shown in Fig. 8 and the retrieved absorption and extinction Angstrom exponents (AAE and EAE) are shown in Fig. 9.

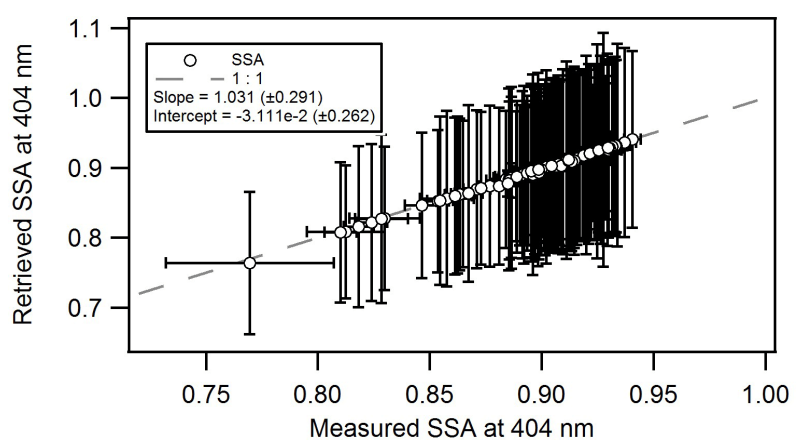

Figure 7. Comparison between the retrieved and measured singlescattering albedo (SSA) values at $404 \mathrm{~nm}$. The retrieved SSA is calculated from the retrieved extinction and scattering coefficients ( $\alpha_{\text {ext }}(t)$ and $\alpha_{\text {sca }}(t)$, respectively), while the measured SSA is calculated from the values of $\alpha_{\text {ext }}(t)$ and $\alpha_{\text {abs }}(t)$ obtained through direct measurement by the single-wavelength photo acoustic spectrometer coupled to a cavity ring-down aerosol spectrometer (PACRD-S).

The retrieved effective complex RI is shown in Fig. 10. Discontinuity in the sampling data is due to routinely performed reflectivity and zero air measurements required to avoid data drifts. Figure S5 shows the evolution of the total number concentration and the SMPS size distributions, normalized to the concentration of the mode diameter.

Between 06:30 and 08:00 during the morning rush hour, an increase in $\alpha_{\text {abs }}$ and a decrease in the size-weighted SSA is not apparent in the extinction and scattering coefficients (Fig. 8). This could be related to increased emissions of ultrafine light-absorbing combustion particles from traffic. This is supported by the decrease in the aerosol size shown in Fig. S5 and by the fact that SSA is directly related to particle size. The apparent effect of transportation during the morning rush hour is also evident in a decrease of the AAE in Figure 9. BC from car emissions can increase the absorption throughout the spectrum but decrease its spectral dependence. A notable increase in the extinction and scattering coefficients seen between 10:00 and 11:00 (Fig. 8) corresponds to the increase in particle concentration seen in Fig. S5 and is due probably to relatively large particles, as the SSA values are relatively high.

Considerable variations in particle number concentration and size distribution occur during the daytime (Fig. S5) and are probably due to transportation on nearby roads. The SMPS size scan duration was set to $5 \mathrm{~min}$ while large concentration variations occurred at shorter timescales. Unlike the $\alpha_{\text {ext }}(\lambda, t), \alpha_{\text {sca }}(\lambda, t), \alpha_{\text {abs }}(\lambda, t)$, and $\operatorname{SSA}(\lambda, t)$ data, the retrieval of the effective complex RI strongly depends on accurate representation of the size distribution and aerosol particle number concentration. For this reason, Fig. 10 shows effective RI retrieval results between midnight and 08:00, when variations in number concentration and size distribution data were not as frequent. The figure shows that the ambient ur- 

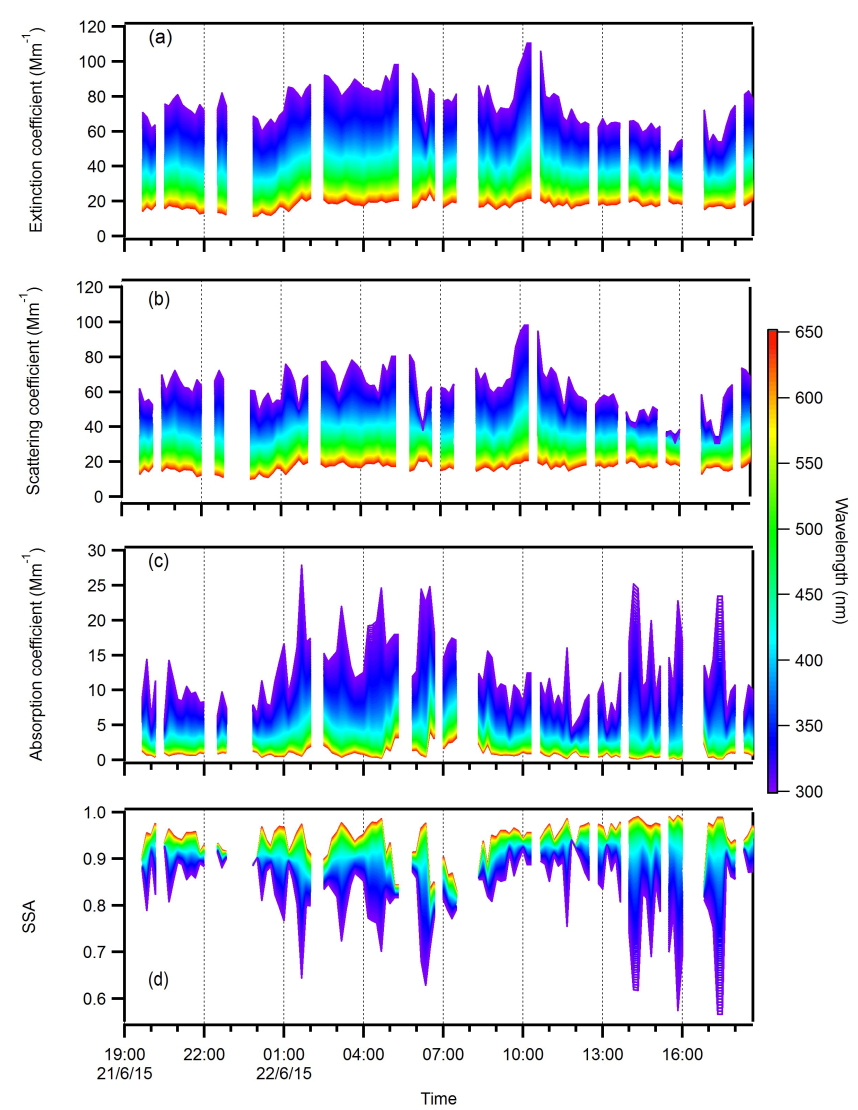

Figure 8. Time series of the retrieved coefficients for extinction (a), scattering (b), absorption (c), and of the single-scattering albedo (SSA) (d) for the 300 to $650 \mathrm{~nm}$ wavelength range of dried ambient aerosols.

ban atmosphere is dominated by slightly absorbing aerosol ( $k$ about 0.03 in the short wavelengths), with a few peaks of more absorbing aerosol with higher $k$ values (up to 0.04 in the shorter wavelengths). Figure 10 also demonstrates higher $k$ values in the long wavelengths with lower spectral dependency (lower AAE) during the morning hours probably due to contribution of BC. In field applications, a large volume with long residence time of the sampled air can be added to the system to reduce variations in aerosol concentration.

In a recent review, Moise et al. (2015) compiled the optical properties data of secondary organic aerosols (SOAs) and $\mathrm{BrC}$ from laboratory and chamber experiments and from ambient measurements reported in various studies. The compiled data were reported based on formation, aging pathways, and chemical composition. Various measurements of laboratory- and chamber-generated anthropogenic / biogenic SOAs at $405 \mathrm{~nm}$ wavelength produced complex RIs with $1.45 \leq n \leq 1.7$ and $0 \leq k \leq 0.04$. The retrieval presented in Fig. 10 mostly falls within the lower limit of this wide range. As Moise et al. (2015) point out, laboratory- and chambergenerated SOAs are mostly not as oxidized as reported ambient aerosols and, although some studies showed a possible

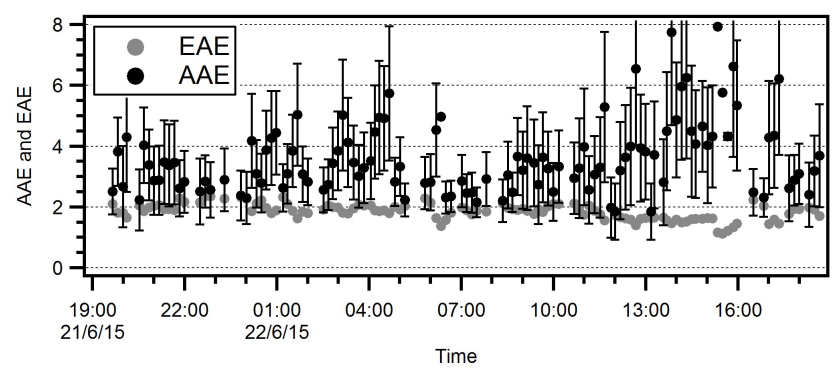

Figure 9. Time series of the retrieved absorption and extinction Angstrom exponents (AAE and EAE) for the 300 to $650 \mathrm{~nm}$ wavelength range.

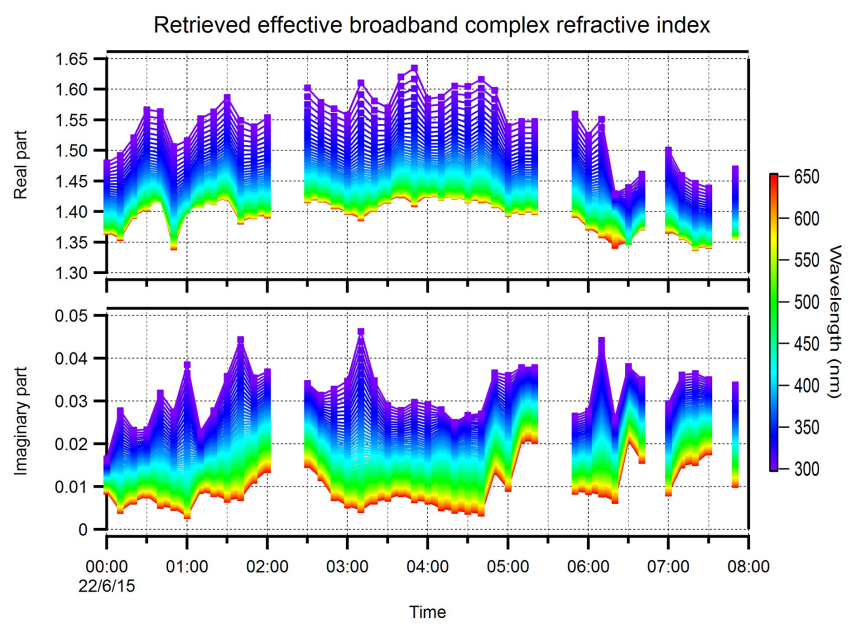

Figure 10. Time series (nighttime hours) of the real and imaginary components of the retrieved effective complex refractive index for the 300 to $650 \mathrm{~nm}$ wavelength range of dried ambient aerosols.

inverse relation between the real part of the complex RI and O / C ratio (Nakayama et al., 2012; Lambe et al., 2013), others reported the opposite (Cappa et al., 2011; Nakayama et al., 2013). The spectral-dependent data compiled by Moise et al. (2015) clearly indicate that measurements of the broadband optical properties of ambient aerosols are scarce. This new retrieval approach is expected to contribute to future understanding of the optical properties of atmospheric aerosols.

\section{Conclusions}

We have developed a new approach to retrieve the timedependent broad spectrum optical properties of ambient aerosols between 300 and $650 \mathrm{~nm}$. Obtaining these properties over such a broad wavelength span and at a high time resolution can contribute considerably to our understanding of aerosol optical properties and their subsequent contribution to radiative forcing. Our approach is based on fitting and extrapolating instrumental extinction, scattering, and absorption data. In this study, the extinction coefficients were ob- 
tained using a homebuilt broadband cavity-enhanced spectrometer measuring at two distinct wavelength ranges: 315 to $345 \mathrm{~nm}$ and 390 to $420 \mathrm{~nm}$. Extinction and absorption coefficients at $\lambda=404 \mathrm{~nm}$ were measured using a photoacoustic spectrometer coupled to a cavity ring-down spectrometer. The scattering coefficients at 457,525 , and $637 \mathrm{~nm}$ were measured using an IN. Although the basic principles of the presented calculations may be used to represent ambient aerosol optical properties over any spectral range, depending on available instrumentation, it is important to investigate the weaknesses of the approach at spectral ranges beyond the instrumental wavelengths.

Computer simulations showed that at the selected spectral range (300 to $650 \mathrm{~nm}$ ) and for a wide atmospherically relevant range of effective complex refractive indices, the expected errors in the size-weighted, wavelength- and timedependent single-scattering albedo, extinction, and scattering coefficients and in the real part of the effective complex RI are mostly less than $\pm 10 \%$. Although the relative errors in the imaginary part of the effective complex RI and in the wavelength- and time-dependent absorption coefficients are expected to grow with increasing wavelength (as these parameters diminish), for a total column radiative transfer calculation the corresponding absolute errors would be negligible. For example, under the conditions of this simulation, at $400 \mathrm{~nm}$, the absolute errors on retrieved $\alpha_{\text {abs }}$ and $k$ are in the range of 1 to $3 \mathrm{Mm}^{-1}$ and 0.01 to 0.015 , respectively.

In previous CRD-S and BBCES studies, the complex RI of aerosols was retrieved from extinction measurements of sizeselected aerosols. Our measurements of ambient aerosols and lab-generated brown carbon proxy aerosols demonstrate the effectiveness of the new approach for laboratory, chamber, and ambient studies, where aerosol size selection may not be achieved due to low number concentrations or a lack of sufficiently large particles. Retrieving the total distribution complex effective RI is significantly faster compared with size selective measurements, which are often used in order to derive aerosol refractive indices. It also minimizes possible errors arising from multiply charged particles (Miles et al., 2011) and from partial representation of the total size distribution due to limitations in the selectable size range. This study presents a first comparison between these two measurement approaches.

Application of the method to the continuous monitoring of ambient aerosols provides extensive and intensive timeand spectrally dependent aerosol optical properties that may be applied in a variety of studies, such as investigations of the effect of chemical aging and SOA formation mechanisms or of hygroscopicity on the spectral dependency of optical properties. It also emphasizes the sensitivity of the retrieval of the total distribution effective complex RI to fast changes in particle size distribution and concentration.

\section{The Supplement related to this article is available online at doi:10.5194/amt-9-3477-2016-supplement.}

Acknowledgements. This research was partially funded by a grant from the German Israeli Science foundation (GIF), project no. 1136-26.8/2011 and by the USA-Israel Binational Science Foundation (BSF) grant no. 2012013. YR acknowledges support from the Dollond Charitable Trust. The SPARTAN station in Rehovot was supported by the Environmental Health Fund (grant no. PGA 1402) and by the Weizmann Institute. NB acknowledges support from the Helen Kimmel Center for Planetary Sciences at the Weizmann Institute.

Edited by: A. Kokhanovsky

Reviewed by: five anonymous referees

\section{References}

Allen, R. J. and Sherwood, S. C.: Aerosol-cloud semi-direct effect and land-sea temperature contrast in a gcm, Geophys. Res. Lett., 37, L07702, doi:10.1029/2010GL042759, 2010.

Andreae, M. O. and Gelencsér, A.: Black carbon or brown carbon? The nature of light-absorbing carbonaceous aerosols, Atmos. Chem. Phys., 6, 3131-3148, doi:10.5194/acp-6-3131-2006, 2006.

Ångström, A.: On the atmospheric transmission of sun radiation and on dust in the air, Geogr. Ann., 11, 156-166, 1929.

Ångström, A.: On the atmospheric transmission of sun radiation, Ii, Geogr. Ann., 12, 130-159, 1930.

Ångström, A.: Echniques of determinig the turbidity of the atmosphere, Tellus, 13, 214-223, 1961.

Ångström, A.: The parameters of atmospheric turbidity, Tellus, 16, 64-75, 1964.

Arnott, W. P., Moosmuller, H., Rogers, C. F., Jin, T. F., and Bruch, R.: Photoacoustic spectrometer for measuring light absorption by aerosol: Instrument description, Atmos. Environ., 33, 28452852, 1999.

Bluvshtein, N., Flores, J. M., Riziq, A. A., and Rudich, Y.: An approach for faster retrieval of aerosols' complex refractive index using cavity ring-down spectroscopy, Aerosol. Sci. Tech., 46, 1140-1150, 2012.

Bohren, C. F. and Huffman, D. R.: Absorption and scattering by a sphere, in: Absorption and scattering of light by small particles, Wiley-VCH Verlag GmbH, 82-129, 2007a.

Bohren, C. F. and Huffman, D. R.: Appendix a: Homogeneous sphere, in: Absorption and scattering of light by small particles, Wiley-VCH Verlag GmbH, 477-482, 2007b.

Bond, T. C., Habib, G., and Bergstrom, R. W.: Limitations in the enhancement of visible light absorption due to mixing state, J. Geophys. Res.-Atmos., 111, D20211, doi:10.1029/2006jd007315, 2006.

Bulatov, V., Fisher, M., and Schechter, I.: Aerosol analysis by cavity-ring-down laser spectroscopy, Anal. Chim. Acta., 466, 19, 2002. 
Cappa, C. D., Che, D. L., Kessler, S. H., Kroll, J. H., and Wilson, K. R.: Variations in organic aerosol optical and hygroscopic properties upon heterogeneous oh oxidation, J. Geophys. Res.-Atmos., 116, D15204, doi:10.1029/2011jd015918, 2011.

Cappa, C. D., Onasch, T. B., Massoli, P., Worsnop, D. R., Bates, T. S., Cross, E. S., Davidovits, P., Hakala, J., Hayden, K. L., Jobson, B. T., Kolesar, K. R., Lack, D. A., Lerner, B. M., Li, S. M., Mellon, D., Nuaaman, I., Olfert, J. S., Petaja, T., Quinn, P. K., Song, C., Subramanian, R., Williams, E. J., and Zaveri, R. A.: Radiative absorption enhancements due to the mixing state of atmospheric black carbon, Science, 337, 1078-1081, 2012.

Chartier, R. T. and Greenslade, M. E.: Initial investigation of the wavelength dependence of optical properties measured with a new multi-pass Aerosol Extinction Differential Optical Absorption Spectrometer (AE-DOAS), Atmos. Meas. Tech., 5, 709-721, doi:10.5194/amt-5-709-2012, 2012.

Chen, Y. and Bond, T. C.: Light absorption by organic carbon from wood combustion, Atmos. Chem. Phys., 10, 1773-1787, doi:10.5194/acp-10-1773-2010, 2010.

Davidi, A., Koren, I., and Remer, L.: Direct measurements of the effect of biomass burning over the Amazon on the atmospheric temperature profile, Atmos. Chem. Phys., 9, 8211-8221, doi:10.5194/acp-9-8211-2009, 2009.

Dinar, E., Riziq, A. A., Spindler, C., Erlick, C., Kiss, G., and Rudich, Y.: The complex refractive index of atmospheric and model humic-like substances (hulis) retrieved by a cavity ring down aerosol spectrometer (crd-as), 137, 279-295, 2008.

Feng, Y., Ramanathan, V., and Kotamarthi, V. R.: Brown carbon: a significant atmospheric absorber of solar radiation?, Atmos. Chem. Phys., 13, 8607-8621, doi:10.5194/acp-13-8607-2013, 2013.

Flores, J. M., Bar-Or, R. Z., Bluvshtein, N., Abo-Riziq, A., Kostinski, A., Borrmann, S., Koren, I., Koren, I., and Rudich, Y.: Absorbing aerosols at high relative humidity: linking hygroscopic growth to optical properties, Atmos. Chem. Phys., 12, 55115521, doi:10.5194/acp-12-5511-2012, 2012.

Flores, J. M., Washenfelder, R. A., Adler, G., Lee, H. J., Segev, L., Laskin, J., Laskin, A., Nizkorodov, S. A., Brown, S. S., and Rudich, Y.: Complex refractive indices in the near-ultraviolet spectral region of biogenic secondary organic aerosol aged with ammonia, Phys. Chem. Chem. Phys., 16, 10629-10642, 2014.

Gaffney, J. S., Marley, N. A., and Smith, K. J.: Characterization of fine mode atmospheric aerosols by raman microscopy and diffuse reflectance ftir, J. Phys. Chem. A, 119, 4524-4532, 2015.

Garg, S., Chandra, B. P., Sinha, V., Sarda-Esteve, R., Gros, V., and Sinha, B.: Limitation of the use of the absorption angstrom exponent for source apportionment of equivalent black carbon: A case study from the north west indo-gangetic plain, Environ. Sci. Technol., 50, 814-824, 2016.

Graber, E. R. and Rudich, Y.: Atmospheric HULIS: How humic-like are they? A comprehensive and critical review, Atmos. Chem. Phys., 6, 729-753, doi:10.5194/acp-6-729-2006, 2006.

Guyon, P., Boucher, O., Graham, B., Beck, J., Mayol-Bracero, O. L., Roberts, G. C., Maenhaut, W., Artaxo, P., and Andreae, M. O.: Refractive index of aerosol particles over the amazon tropical forest during lba-eustach 1999, J. Aerosol. Sci., 34, 883-907, 2003.

Hilfiker, J. N., Singh, N., Tiwald, T., Convey, D., Smith, S. M., Baker, J. H., and Tompkins, H. G.: Survey of methods to charac- terize thin absorbing films with spectroscopic ellipsometry, Thin Solid Films, 516, 7979-7989, 2008.

Hill, A. A., and Dobbie, S.: The impact of aerosols on nonprecipitating marine stratocumulus. Ii: The semi-direct effect, Q. J. Roy. Meteor. Soc., 134, 1155-1165, 2008.

Hoffer, A., Gelencsér, A., Guyon, P., Kiss, G., Schmid, O., Frank, G. P., Artaxo, P., and Andreae, M. O.: Optical properties of humic-like substances (HULIS) in biomass-burning aerosols, Atmos. Chem. Phys., 6, 3563-3570, doi:10.5194/acp-6-3563-2006, 2006.

IPCC: Climate change 2013: The physical science basis. Contribution of working group i to the fifth assessment report of the intergovernmental panel on climate change, Cambridge University Press, Cambridge, United Kingdom and New York, NY, USA, 1535 pp., 2013.

Islam, M., Ciaffoni, L., Hancock, G., and Ritchie, G. A.: Demonstration of a novel laser-driven light source for broadband spectroscopy between $170 \mathrm{~nm}$ and $2.1 \mathrm{mum}$, The Analyst, 138, 47414745, 2013.

Jordan, C. E., Anderson, B. E., Beyersdorf, A. J., Corr, C. A., Dibb, J. E., Greenslade, M. E., Martin, R. F., Moore, R. H., Scheuer, E., Shook, M. A., Thornhill, K. L., Troop, D., Winstead, E. L., and Ziemba, L. D.: Spectral aerosol extinction (SpEx): a new instrument for in situ ambient aerosol extinction measurements across the UV/visible wavelength range, Atmos. Meas. Tech., 8 , 4755-4771, doi:10.5194/amt-8-4755-2015, 2015.

Kirchstetter, T. W., Novakov, T., and Hobbs, P. V.: Evidence that the spectral dependence of light absorption by aerosols is affected by organic carbon, J. Geophys. Res.-Atmos., 109, D21208, doi:10.1029/2004jd004999, 2004.

Koch, D. and Del Genio, A. D.: Black carbon semi-direct effects on cloud cover: review and synthesis, Atmos. Chem. Phys., 10, 7685-7696, doi:10.5194/acp-10-7685-2010, 2010.

Lack, D. A., Lovejoy, E. R., Baynard, T., Pettersson, A., and Ravishankara, A. R.: Aerosol absorption measurement using photoacoustic spectroscopy: Sensitivity, calibration, and uncertainty developments, Aerosol. Sci. Tech., 40, 697-708, 2006.

Lack, D. A., Richardson, M. S., Law, D., Langridge, J. M., Cappa, C. D., McLaughlin, R. J., and Murphy, D. M.: Aircraft instrument for comprehensive characterization of aerosol optical properties, part 2: Black and brown carbon absorption and absorption enhancement measured with photo acoustic spectroscopy, Aerosol. Sci. Tech., 46, 555-568, 2012.

Lambe, A. T., Cappa, C. D., Massoli, P., Onasch, T. B., Forestieri, S. D., Martin, A. T., Cummings, M. J., Croasdale, D. R., Brune, W. H., Worsnop, D. R., and Davidovits, P.: Relationship between oxidation level and optical properties of secondary organic aerosol, Environ. Sci. Technol., 47, 6349-6357, 2013.

Lan, Z. J., Huang, X. F., Yu, K. Y., Sun, T. L., Zeng, L. W., and Hu, M.: Light absorption of black carbon aerosol and its enhancement by mixing state in an urban atmosphere in south china, Atmos. Environ., 69, 118-123, 2013.

Laskin, A., Laskin, J., and Nizkorodov, S. A.: Chemistry of atmospheric brown carbon, Chem. Rev., 115, 4335-4382, 2015.

Lavi, A., Bluvshtein, N., Segre, E., Segev, L., Flores, M., and Rudich, Y.: Thermochemical, cloud condensation nucleation ability, and optical properties of alkyl aminium sulfate aerosols, J. Phys. Chem. C, 117, 22412-22421, 2013. 
Miles, R. E. H., Rudic, S., Orr-Ewing, A. J., and Reid, J. P.: Sources of error and uncertainty in the use of cavity ring down spectroscopy to measure aerosol optical properties, Aerosol. Sci. Tech., 45, 1360-1375, 2011.

Moise, T., Flores, J. M., and Rudich, Y.: Optical properties of secondary organic aerosols and their changes by chemical processes, Chem. Rev., 115, 4400-4439, 2015.

Nabat, P., Somot, S., Mallet, M., Sevault, F., Chiacchio, M., and Wild, M.: Direct and semi-direct aerosol radiative effect on the mediterranean climate variability using a coupled regional climate system model, Clim. Dynam., 44, 1127-1155, 2014.

Nagele, M. and Sigrist, M. W.: Mobile laser spectrometer with novel resonant multipass photoacoustic cell for trace-gas sensing, Appl. Phys. B-Lasers. O., 70, 895-901, 2000.

Nakayama, T., Matsumi, Y., Sato, K., Imamura, T., Yamazaki, A., and Uchiyama, A.: Laboratory studies on optical properties of secondary organic aerosols generated during the photooxidation of toluene and the ozonolysis of $\alpha$-pinene, 115, D24204, doi:10.1029/2010jd014387, 2010.

Nakayama, T., Sato, K., Matsumi, Y., Imamura, T., Yamazaki, A., and Uchiyama, A.: Wavelength dependence of refractive index of secondary organic aerosols generated during the ozonolysis and photooxidation of alpha-pinene, Sola, 8, 119-123, doi:10.2151/sola.2012-030, 2012.

Nakayama, T., Sato, K., Matsumi, Y., Imamura, T., Yamazaki, A., and Uchiyama, A.: Wavelength and NOx dependent complex refractive index of SOAs generated from the photooxidation of toluene, Atmos. Chem. Phys., 13, 531-545, doi:10.5194/acp-13531-2013, 2013.

Pettersson, A., Lovejoy, E. R., Brock, C. A., Brown, S. S., and Ravishankara, A. R.: Measurement of aerosol optical extinction at $532 \mathrm{~nm}$ with pulsed cavity ring down spectroscopy, J. Aerosol. Sci., 35, 995-1011, 2004.

Press, W. H., Teukolsky, S. A., Vetterling, W. T., and Flannery, B. P.: Numerical recipes in c: The art of scientific computing, Cambridge University Press, 2nd ed., 697-703, 1992.

Riziq, A. A., Erlick, C., Dinar, E., and Rudich, Y.: Optical properties of absorbing and non-absorbing aerosols retrieved by cavity ring down (CRD) spectroscopy, Atmos. Chem. Phys., 7, 1523-1536, doi:10.5194/acp-7-1523-2007, 2007.

Russell, P. B., Bergstrom, R. W., Shinozuka, Y., Clarke, A. D., DeCarlo, P. F., Jimenez, J. L., Livingston, J. M., Redemann, J., Dubovik, O., and Strawa, A.: Absorption Angstrom Exponent in AERONET and related data as an indicator of aerosol composition, Atmos. Chem. Phys., 10, 1155-1169, doi:10.5194/acp-101155-2010, 2010.

Sappey, A. D., Hill, E. S., Settersten, T., and Linne, M. A.: Fixedfrequency cavity ringdown diagnostic for atmospheric particulate matter, Opt. Lett., 23, 954-956, 1998.

Smith, J. D. and Atkinson, D. B.: A portable pulsed cavity ringdown transmissometer for measurement of the optical extinction of the atmospheric aerosol, The Analyst, 126, 1216-1220, 2001.

Snider, G., Weagle, C. L., Martin, R. V., van Donkelaar, A., Conrad, K., Cunningham, D., Gordon, C., Zwicker, M., Akoshile, C., Artaxo, P., Anh, N. X., Brook, J., Dong, J., Garland, R. M., Greenwald, R., Griffith, D., He, K., Holben, B. N., Kahn, R., Koren, I., Lagrosas, N., Lestari, P., Ma, Z., Vanderlei Martins, J., Quel, E. J., Rudich, Y., Salam, A., Tripathi, S. N., Yu, C., Zhang, Q., Zhang, Y., Brauer, M., Cohen, A., Gibson, M. D., and Liu, Y.: SPARTAN: a global network to evaluate and enhance satellite-based estimates of ground-level particulate matter for global health applications, Atmos. Meas. Tech., 8, 505-521, doi:10.5194/amt-8-505-2015, 2015.

Spracklen, D. V., Jimenez, J. L., Carslaw, K. S., Worsnop, D. R., Evans, M. J., Mann, G. W., Zhang, Q., Canagaratna, M. R., Allan, J., Coe, H., McFiggans, G., Rap, A., and Forster, P.: Aerosol mass spectrometer constraint on the global secondary organic aerosol budget, Atmos. Chem. Phys., 11, 12109-12136, doi:10.5194/acp-11-12109-2011, 2011.

Strawa, A. W., Castaneda, R., Owano, T., Baer, D. S., and Paldus, B. A.: The measurement of aerosol optical properties using continuous wave cavity ring-down techniques, J. Atmos. Ocean. Tech., 20, 454-465, 2003.

Sun, H. L., Biedermann, L., and Bond, T. C.: Color of brown carbon: A model for ultraviolet and visible light absorption by organic carbon aerosol, Geophys. Res. Lett., 34, L17813, doi:10.1029/2007g1029797, 2007.

Thompson, J. E., Smith, B. W., and Winefordner, J. D.: Monitoring atmospheric particulate matter through cavity ring-down spectroscopy, Anal. Chem., 74, 1962-1967, 2002.

Trainic, M., Abo Riziq, A., Lavi, A., Flores, J. M., and Rudich, Y.: The optical, physical and chemical properties of the products of glyoxal uptake on ammonium sulfate seed aerosols, Atmos. Chem. Phys., 11, 9697-9707, doi:10.5194/acp-11-96972011, 2011.

Valenzuela, A., Olmo, F. J., Lyamani, H., Anton, M., Titos, G., Cazorla, A., and Alados-Arboledas, L.: Aerosol scattering and absorption angstrom exponents as indicators of dust and dust-free days over granada (spain), Atmos. Res., 154, 1-13, 2015.

Vander Wal, R. L. and Ticich, T. M.: Cavity ringdown and laserinduced incandescence measurements of soot, Appl. Opt., 38, 1444-1451, 1999.

Varma, R. M., Ball, S. M., Brauers, T., Dorn, H.-P., Heitmann, U., Jones, R. L., Platt, U., Pöhler, D., Ruth, A. A., Shillings, A. J. L., Thieser, J., Wahner, A., and Venables, D. S.: Light extinction by secondary organic aerosol: an intercomparison of three broadband cavity spectrometers, Atmos. Meas. Tech., 6, 3115-3130, doi:10.5194/amt-6-3115-2013, 2013.

Washenfelder, R. A., Flores, J. M., Brock, C. A., Brown, S. S., and Rudich, Y.: Broadband measurements of aerosol extinction in the ultraviolet spectral region, Atmos. Meas. Tech., 6, 861-877, doi:10.5194/amt-6-861-2013, 2013.

Washenfelder, R. A., Attwood, A. R., Brock, C. A., Guo, H., Xu, L., Weber, R. J., Ng, N. L., Allen, H. M., Ayres, B. R., Baumann, K., Cohen, R. C., Draper, D. C., Duffey, K. C., Edgerton, E., Fry, J. L., Hu, W. W., Jimenez, J. L., Palm, B. B., Romer, P., Stone, E. A., Wooldridge, P. J., and Brown, S. S.: Biomass burning dominates brown carbon absorption in the rural southeastern united states, Geophys. Res. Lett., 42, 653-664, 2015.

Washenfelder, R. A., Attwood, A. R., Flores, J. M., Zarzana, K. J., Rudich, Y., and Brown, S. S.: Broadband cavity-enhanced absorption spectroscopy in the ultraviolet spectral region for measurements of nitrogen dioxide and formaldehyde, Atmos. Meas. Tech., 9, 41-52, doi:10.5194/amt-9-41-2016, 2016.

Yuan, J.-F., Huang, X.-F., Cao, L.-M., Cui, J., Zhu, Q., Huang, C.N., Lan, Z.-J., and He, L.-Y.: Light absorption of brown carbon aerosol in the PRD region of China, Atmos. Chem. Phys., 16, 1433-1443, doi:10.5194/acp-16-1433-2016, 2016. 
Zarzana, K. J., Cappa, C. D., and Tolbert, M. A.: Sensitivity of aerosol refractive index retrievals using optical spectroscopy, Aerosol. Sci. Tech., 48, 1133-1144, 2014.

Zhang, X., Huang, Y., Rao, R., and Wang, Z.: Retrieval of effective complex refractive index from intensive measurements of characteristics of ambient aerosols in the boundary layer, Optics express, 21, 17849-17862, 2013.
Zhao, W., Dong, M., Chen, W., Gu, X., Hu, C., Gao, X., Huang, W., and Zhang, W.: Wavelength-resolved optical extinction measurements of aerosols using broad-band cavity-enhanced absorption spectroscopy over the spectral range of $445-480 \mathrm{~nm}$, Anal. Chem., 85, 2260-2268, 2013. 